Rev. Latinoam. Psicopat. Fund., São Paulo, 20(3), 605-608, set. 2017

http://dx.doi.org/10.1590/1415-4714.2017v20n3p605-13

The future of Trauma Theory:

Contemporary Literary and Cultural Critiscim

Gert Beulens, Sam Durrant \& Robert Eaglestone (Eds.)

London/New York:

Routledge, 2014, 182 págs.

\title{
Futuros possíveis para a Teoria do Trauma
}

\author{
Daniel Boianovsky Kveller*1
}

Simone Zanon Moschen*2

Costuma-se denominar por Trauma Studies (Estudos sobre o Trauma) um conjunto de pesquisas interdisciplinares estadunidenses e europeias - notadamente influenciadas pela Psicanálise e pela Teoria Literária - que se valem do conceito de trauma como uma chave de leitura e análise das grandes "catástrofes" que marcaram o século XX e início do século XXI. Os trabalhos fundadores deste campo, e ainda hoje reconhecidos como canônicos, foram desenvolvidos por Cathy Caruth, Soshana Felman, Dori Laub, Dominick LaCapra e outros durante os anos 1990. Tais estudos tiveram como foco principal a Shoah, o holocausto judaico, e foram fundamentais para o desenvolvimento de pesquisas sobre a relação entre trauma, violência, testemunho e história. Ainda que a maior parte

*1 Doutorando pela Universidade Federal do Rio Grande do Sul - UFRGS (Porto Alegre, RS. Br).

*2 Universidade Federal do Rio Grande do Sul - UFRGS (Porto Alegre, RS. Br). 
permaneça indisponível em língua portuguesa, alguns capítulos de livros foram traduzidos e publicados como parte da coletânea Catástrofe e representação (Nestrovski \& Seligmann-Silva, 2000), a qual, por sua vez, tornou-se uma espécie de obra seminal dos Estudos sobre o Trauma em território brasileiro.

Com a consolidação do campo e a consequente profusão do significante "trauma" pelas ciências humanas, os Trauma Studies tornaram-se também alvo de diversas críticas, dentre as quais se destacam aquelas oriundas dos estudos pós-coloniais, focadas essencialmente em tornar visível e examinar o caráter estadunidense-eurocêntrico arraigado nas bases fundantes dessas pesquisas. De forma geral, há um consenso entre os autores pós-coloniais de que a centralidade dos estudos sobre o Holocausto (e do 11 de setembro, pode-se dizer também) limitaria substancialmente o alcance das análises baseadas no conceito de trauma para outros contextos, como países africanos e do Oriente Médio, onde as marcas subjetivas da colonização se refletem de maneiras bastante distintas, inclusive do ponto de vista psicopatológico. Para que isso se torne possível, o modelo do traumatismo baseado na vivência de um ou mais eventos aterrorizantes, inesperados e incontroláveis precisaria ser 606 revisto para contemplar situações em que o contato com a violência extrema se daria de forma estrutural ou mesmo contínua.

O livro The Future of Trauma Theory: Contemporary Literary and Cultural Criticism, organizado por Gert Buelens, Sam Durrant e Robert Eaglestone, tem justamente nessas críticas o seu ponto de partida. No entanto, como observa Michael Rothberg no prefácio, o objetivo geral da coletânea de ensaios não é ratificá-las ou rebatê-las, mas apontar novos caminhos capazes de reafirmar a potência dos Trauma Studies, alargando seus horizontes no quadro geral dos estudos pós-coloniais. Em outras palavras, não se trata de advogar a supressão da dimensão traumática das análises históricas e sociológicas, mas de politizar a própria noção de trauma, de modo a mantê-la como uma ferramenta útil para a compreensão das relações subjetivas entre violência e memória em contextos não ocidentais.

Os dez capítulos que compõem o livro estão divididos em duas seções. A primeira, intitulada "History and Culture", reúne ensaios que buscam explicitar como as narrativas pós-traumáticas de países não ocidentais desafiam as noções tradicionais de testemunho, elaboração e sofrimento, convocando um reposicionamento crítico da teoria. Entre os temas de exame encontram-se a literatura libanesa pós-guerra civil, a poesia talibã, a construção do Museu do Genocídio Tuol Sleng no Camboja, e o estilo de música e dança angolanos 


\section{RESENHAS BIBLIOGRÁFICAS}

Kuduro. Já a segunda seção, "Politics and Subjectivity", dá lugar a ensaios acentuadamente teóricos que focam as transformações da relação entre Estado, comunidade e subjetividade características do mundo globalizado, e as consequentes novas formas de violência surgidas nessa conjuntura. A questão dos refugiados é discutida, a partir da obra de Hannah Arendt, assim como as relações entre trauma e a biopolítica, o sujeito desaparecido como figura paradigmática da política contemporânea, além da ficção científica como um gênero narrativo inexplorado, mas, potencialmente profícuo para os estudos do trauma.

À primeira vista, The Future of Trauma Theory pode parecer desafiador, já que se insere em um debate ainda pouco traduzido no país e não traz discussões relacionadas diretamente ao contexto brasileiro ou mesmo latino-americano. Todavia, considerando que os estudos sobre trauma vêm ganhando especial importância e visibilidade desde o aniversário de 50 anos do golpe civil-militar de 1964, é necessário que reflitamos sobre as potências e os limites dessas análises para a compreensão das lógicas de reprodução da violência no Brasil e seus efeitos em nível psicopatológico. Afinal, se o modelo baseado em evento(s) é conveniente para análises sobre os efeitos da violência de Estado característicos da ditadura civil-militar; violências estruturais e muitas vezes naturalizadas - como o racismo e o sexismo, por exemplo - certamente demandam uma aproximação diferenciada, que apenas o diálogo interdisciplinar pode oferecer.

De forma resumida, pode-se dizer que The Future of Trauma Theory propõe um desafio aos pesquisadores da psicanálise e da psicopatologia fundamental no Brasil: não apenas considerar a noção de trauma como uma ferramenta útil na análise das formas de mal-estar na cultura brasileira contemporânea, mas, também, refletir sobre a própria singularidade do nosso contexto como possibilidade de construção crítica de uma teoria psicanalítica não colonizada.

\section{Referências}

Nestrovski, A. R., \& Seligmann-Silva, M. (2000). Catástrofe e representação. São Paulo, SP: Escuta. 


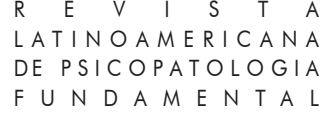

Citação/Citation: Kveller, D. B., \& Moschen, S. Z. (2017, setembro). Futuros possíveis para a teoria do trauma. Resenha do livro The Future of Trauma Theory: Contemporary Literary and Cultural Criticism. Revista Latinoamericana de Psicopatologia Fundamental, 20(3), 605-608. http://dx.doi.org/10.1590/1415-4714.2017v20n3p605.13

Editores do artigo/Editors: Profa. Dra. Sonia Leite

Recebido/Received: 17.3.2017/3.17.2017 Aceito/Accepted: 29.3.2017/3.29.2017

Copyright: (C) 2009 Associação Universitária de Pesquisa em Psicopatologia Fundamental/ University Association for Research in Fundamental Psychopathology. Este é um artigo de livre acesso, que permite uso irrestrito, distribuição e reprodução em qualquer meio, desde que o autor e a fonte sejam citados / This is an open-access article, which permits unrestricted use, distribution, and reproduction in any medium, provided the original authors and sources are credited.

\section{Daniel Boianovsky Kveller}

Doutorando em Psicologia Social e Institucional pela Universidade Federal do Rio Grande do Sul - UFRGS (Porto Alegre, RS, Br).

Rua Tiradentes, 82/1204 - Bairro Independência

90560-030 Porto Alegre, RS, Br

dkveller@gmail.com

\section{Simone Zanon Moschen}

Doutora em Educação pela Universidade Federal do Rio Grande do Sul - UFRGS (Porto Alegre, RS, Br); Professora nos Programas de Pós-Graduação em Educação e Psicanálise: Clínica e Cultura na mesma Universidade.

Rua Tomas Gonzaga, 430/08 - Bairro Boa Vista

91340-480 Porto Alegre, RS, Br

simoschen@gmail.com

This is an open-access article, which permits unrestricted use, distribution, and reproduction in any medium for non-commercial purposes provided the original authors and sources are credited. 